\title{
Educación artística y autonomía universitaria en México: orígenes de la Orquesta Sinfónica de la Universidad Nacional $(1929-1936)^{1}$ \\ José-Ángel Beristáin-Cardoso
}

\section{RESUMEN}

Este artículo tiene como principal objetivo develar los orígenes de la Orquesta Sinfónica de la Universidad Nacional en sus distintos momentos nodales: el conflicto de autonomía y la segregación de los músicos del conservatorio, la creación de la facultad de música y la organización de su propia orquesta dentro de un campo en un tiempo y espacio definido, en el contexto de los gobiernos posrevolucionarios. En este campo se discutieron y debatieron los problemas comunes en lugares comunes como sucedió en las sesiones extraordinarias de las asambleas para la creación de una nueva escuela de música universitaria. En esta investigación se sientan bases para el estudio de la transición del Departamento de Extensión Universitaria al Departamento de Acción Social, de la Orquesta de la Facultad de Música a la Orquesta Sinfónica de la Universidad Nacional, así como de la formación integral del músico universitario.

Palabras clave: autonomía, campo, conservatorio, educación, música, orquesta sinfónica, universidad, México.

\section{José-Angel Beristáin-Cardoso}

Mexicano. Doctor en Historia y Etnohistoria, Escuela Nacional de Antropología e Historia (ENAH), México. Estancia posdoctoral en el Instituto de Investigaciones Dr. José María Luis Mora, México. Temas de investigacion: Historia social y cultural del patrimonio, instituciones y política cultural en México siglos XIX, xx y XI.

\footnotetext{
${ }^{1}$ Este artículo se desarrolló durante la estancia posdoctoral "UNAM. Programa de Becas Posdoctorales en la UNAM, becario del Instituto de Investigaciones sobre la Universidad y la Educación, asesorado por la doctora Rosalina Ríos Zuñiga, durante el año académico 2018-2019"; dentro del proyecto de investigación "Orquestas y agrupaciones de música de cámara en la Universidad Nacional (1917-1936). La construcción de la identidad en el campo artístico de los músicos universitarios". Mi agradecimiento al doctor Hugo Casanova Cardiel y a la doctora Leticia Pérez Puente por todo el apoyo brindado durante la estancia, a la doctora Rosalina Ríos Zuñiga por su valiosa asesoría y confianza, a la doctora Laura Suárez de la Torre por impulsar mi trabajo de investigación en el ámbito de la historia cultural, y a la dirección y personal del Archivo Histórico de la UNAM por brindarme todas las facilidades en mi trabajo de investigación documental.
} 
Educação artística e autonomia universitária no México: origens da Orquestra Sinfônica da Universidade Nacional (1929-1936)

\section{RESUMO}

Este artigo tem como principal objetivo revelar as origens da Orquestra Sinfônica da Universidade Nacional em seus diferentes momentos decisivos: o conflito de autonomia e a segregação dos músicos do conservatório, a criação da faculdade de música e a organização de sua própria orquestra dentro de um campo em um tempo e espaço definido, no contexto dos governos pós-revolucionários. Neste campo se discutiram e debateram os problemas comuns em lugares comuns como aconteceu nas sessões extraordinárias das assembleias para a criação de uma nova escola de música universitária. Nesta pesquisa se abre o caminho para o estudo da transição do Departamento de "Extensión Universitaria" ao "Departamento de Acción Social”, da Orquestra da Faculdade de Música à Orquestra Sinfônica da Universidade Nacional, assim como da formação integral do músico universitário.

Palavras chave:

Palavras chave: autonomia, campo, conservatório, educação, música, orquestra sinfônica, universidade, México.

\section{Artistic education and university autonomy in Mexico: origins of the National University Symphony Orchestra (1929-1936)}

\section{ABSTRACT}

The main objective of this article is to unveil the origins of the National University Symphonic Orchestra in its different key moments: the conflict of autonomy and the segregation of the musicians of the conservatory, the creation of the music faculty and the organization of its own orchestra within a defined time and space, in the context of the post-revolutionary governments. In this field common problems were discussed and debated in common places as it happened during the extraordinary sessions of the assemblies for the creation of a new university music school. In this research, the author lays a basis for the study of the transition from the University Extension Department to the Social Action Department, from the Music Faculty Orchestra to the National University Symphony Orchestra, as well as for the study of the integral training of the university musician.

Key words: autonomy, field, conservatory, education, music, symphonic orchestra, university, Mexico. 


\section{Introducción}

En los primeros 30 años de la educación artística de la Universidad Nacional sus profesores y estudiantes de música formaron parte de un "campo" con propiedades específicas en un espacio y tiempo definido. En esta investigación me atrevo de nuevo a sustentar esta categoría de análisis basada en la producción de las obras del sociólogo y filósofo francés Pierre Bourdieu (1930-2002); en donde desde una perspectiva de la Historia Cultural, persigo estrechar un fuerte lazo entre las disciplinas de la sociología y la historia como un recurso metodológico, y como diría Lagorio (2015: 17), con una mirada diacrónica y crítica que problematice aspectos que las investigaciones meramente descriptivas llegan a omitir, o simplemente intentan abordar como temas irrelevantes.

Bourdieu sugiere que cada que se estudie un campo determinado se debe intentar descubrir sus propiedades específicas, siendo el principal objetivo de esta investigación develar los argumentos de los debates de los músicos universitarios, de sus problemas en las sesiones extraordinarias de sus asambleas como aquellos lugares comunes de disputa en el impulso del proyecto de creación de la Facultad de Música, así como seguir descubriendo aquellos elementos de pertenencia que fortalecieron la identidad y su proyección en la orquesta sinfónica, antes y después del conflicto de autonomía.

El periodo de estudio de esta investigación (19291936) tiene como momentos nodales: la segregación del Conservatorio de la Universidad Nacional tras el conflicto de autonomía en 1929, la creación de la Facultad de Música en ese mismo año, y el funcionamiento de su propia orquesta para sentar las bases en su evolución como orquesta sinfónica de la Universidad Nacional. Este proceso histórico está permeado por los proyectos de los gobiernos posrevolucionarios y la crisis económica que impactó el inicio de los difíciles años treinta. En el ámbito cultural nos podemos referir a una etapa de articulaciones, definiciones y disputas en lo concerniente a la identidad y ciudadanía. El discurso oficial en esta década estuvo pleno de "referencias a las clases proletarias, a los campesinos, a los intereses del capital, a la lucha contra el imperialismo y a favor de la conciencia de clase; de tal manera que no debía extrañar a nadie que se tildara al régimen posrevolucionario de socializante o de plano socialista" (Pérez, 2015: 159).

Las fuentes documentales que se consultaron pertenecen al Archivo Histórico de la Universidad Nacional Autónoma de México (AHUNAM), acervo que comenzó a organizarse desde 1962, con el objetivo de rescatar la memoria institucional de la máxima casa de estudio de México, cuyos documentos se encontraban dispersos entre distintas dependencias universitarias. Desde 1976 el AHUNAM se integró al entonces Centro de Estudios sobre la Universidad (CESU), hoy conocido como Instituto de Investigaciones sobre la Universidad y la Educación (IISUE); y a partir de ese momento se ha venido consolidando en diferentes etapas, en su teoría y práctica archivística, desarrollo académico, así como en el contacto de la comunidad archivística nacional y de Iberoamérica (Carreño $e t$ al., 2016: 9-11). Entre los documentos analizados correspondientes al Fondo Universidad Nacional (FUN) y Fondo Escuela Nacional de Música (ENM) destacan: actas de asambleas, conferencias, programas de conciertos, memorándums, lista de músicos participantes, tablas de subsidios otorgados a los músicos integrantes de las orquestas, cartas, telegramas, listas de nómina de profesores, informes del Departamento de Extensión Universitaria, pensiones a estudiantes, planes de estudio, tablas de ingresos y egresos de los conciertos realizados, homenajes a profesores distinguidos, invitaciones de dependencias públicas a la orquesta de la universidad, proyectos para la difusión de la orquesta, teoría musical, entre otros. Por otro lado, en lo concerniente con la iconografía, se revisaron imágenes de interesantes fondos como el del fotógrafo Ricardo Salazar Ahumada en el AHUNAM, y del Archivo de Iconoteca del Fondo Reservado en la Biblioteca Nacional. 


\section{El concepto de "campo" en los músicos universitarios}

Desde su fundación, el Conservatorio Nacional de Música (1866) se convirtió en una especie de lugar orgánico en donde se "legitimó" a los músicos mexicanos que ingresaron y se formaron en sus aulas como los "destinatarios titulares" en su acercamiento a la alta cultura ${ }^{2}$ occidental, refiriéndonos a ésta como la fase más elevada del arte entre los siglos XVIII y XIX (conciertos, danza, ópera, entre otras). El conservatorio y la facultad de música como "academias" formaron parte de un sistema de interacciones de un campo intelectual que mantenía relaciones de interdependencia con las estructuras de un campo cultural. ${ }^{3}$ Para Bourdieu (2002a: 83) "la transmisión escolar desempeña siempre una función de legitimación”, y así sucedió en el caso de los músicos universitarios, no sólo por la consagración del legado musical que se transmitió sino también por el espíritu común que se logró en un conjunto de lugares comunes, en donde éstos debatieron sus problemas comunes; parafraseando a Bourdieu "los hombres cultivados de una época determinada pueden estar en desacuerdo sobre los objetos en torno a los cuales disputan, pero al menos están de acuerdo en disputar en torno a los mismos objetos" (2002a: 45-46).

De acuerdo con Bourdieu ${ }^{4}$ en las sociedades modernas la vida social se reproduce en "campos" (económico, político, científico, intelectual y cultural), dentro de un espacio social, es decir dentro de un conjunto de posiciones distintas y coexistentes, "un espacio de diferencias en el cual las clases se encuentran de algún modo en estado virtual, no como algo dado, sino como algo a hacerse" (Bourdieu, 2011: 35). En el campo de los músicos universitarios podemos encontrar elementos esenciales para su constitución, tales como la existencia de un "capital común" (habilidades, conocimientos, creencias, entre otros), así como la lucha por su apropiación o disputa entre quienes detentan el capital y la de quienes aspiran a poseerlo.

En la creación, desarrollo y organización de la facultad de música y su difusión a través de su orquesta, se retomaron ciertos elementos del conservatorio - antes del conflicto de autonomía- que nos ayudan a ejemplificar de manera más clara la lucha o disputa dentro del campo: a) conciertos-homenajes para hacer época remitiendo al pasado, b) músicos dominantes conformes con la continuidad y la identidad de la agrupación, y c) músicos dominados, aquellos que recién entran al campo y pueden hacer la diferencia o la discontinuidad.

Los músicos universitarios lograron dar mayor cohesión a su identidad a través de un conjunto de propiedades establecidas; entre aquellas que propone Bourdieu se incluyen los "títulos puestos al frente de la autopresentación", la "pertenencia universitaria", las "posiciones de poder o de autoridad", y los "títulos universitarios" (2009: 20-21); estos últimos como un efecto de posición simbólica, garantizando "realmente la posesión de una cultura general, tanto más considerable y extensa cuanto más prestigiosa

\footnotetext{
${ }^{2}$ En este aspecto la "cultura popular" queda entonces como una cultura residual, como una forma de acomodar las prácticas culturales que no cumplen con los requisitos para ser cualificados como alta cultura; en otras palabras, la cultura popular quedaría como una cultura inferior. En este rubro John Storey (2002) realiza un interesante esbozo del paisaje conceptual general de la cultura popular en "Teoría cultural y cultura popular".

${ }^{3}$ Para Bourdieu el campo cultural es un sistema de relaciones que incluye a los artistas, críticos, editores y al público; determinando las condiciones específicas de producción y circulación de sus productos.

${ }^{4} \mathrm{Si}$ algún lector desea conocer un poco más sobre la acogida internacional de la obra de Pierre Bourdieu como un "sociólogo global", así como de la circulación internacional de bienes simbólicos a través de la articulación del concepto de "campo" con teorías de otros autores, es indispensable consultar la memoria de las conferencias en México de su discípula Gisèle Sapiro (2017) en "Las condiciones de producción y circulación de los bienes simbólicos”. Como bien señala la historiadora Laura Suárez, presentadora y editora de esta obra, Sapiro "conoce a profundidad su obra y reconoce la importancia del teórico; asume sus propuestas y explora la resonancia que han tenido sus planteamientos en Europa y a lo largo del mundo, en donde la traducción fungió como una vía de socialización de su obra”.
} 
sea la misma" (Bourdieu, 2002b: 22). Para este autor los títulos predisponen y legitiman, y en cuanto a lo académico $^{5}$ designa ciertas condiciones de existencia, que constituyen la condición de la adquisición del título y también de la disposición estética, es decir, de ese reconocimiento de que "toda obra legítima tiende en realidad a imponer las normas de su propia percepción" (2002b: 26). En el caso de los músicos universitarios, su formación artística será vital para conformarse a estas normas, en un campo en el cual "la música es la más espiritualista de las artes del espíritu y el amor a la música es una garantía de espiritualidad" (2002b: 16).

\section{El conservatorio universitario}

Durante el gobierno constitucionalista de Venustiano Carranza se reorganizó la Secretaría de Instrucción Pública, creándose la Dirección General de las Bellas Artes en la cual se insertaría al Conservatorio Nacional de Música y Arte Dramático. En 1916, esta dirección general acordó cambiar el nombre del conservatorio nacional de música ${ }^{6}$ por el de "Escuela Nacional de Música y Arte Teatral", mientras que la antigua orquesta del conservatorio nacional de músi$\mathrm{ca}^{7}$ se denominaría "Orquesta Sinfónica Nacional". Un año después desapareció la Secretaría de Instrucción Pública con la creación de siete secretarías de Estado y cinco departamentos, entre éstos el "Universitario y de Bellas Artes". A este último se incorporó la Universidad Nacional y sus escuelas de Ingeniería, Jurisprudencia y Medicina; contando con un director y rector al mismo tiempo (Beristáin, 2019: 101-102).
El Departamento Universitario y de Bellas Artes convirtió a la universidad en una dependencia burocrática hasta 1920. En ese año José Vasconcelos asumió su jefatura y desarrolló el proyecto de creación de la Secretaría de Educación Pública (SEP) para ponerla en funcionamiento. De esta manera, la Universidad Nacional se integró a la SEP, recuperando varias de sus funciones para la cual fue fundada. En 1921, Vasconcelos impulsó la creación del Departamento de Bellas Artes de la recién fundada SEP, incluyendo en sus secciones al Museo Nacional de Arqueología, Historia y Etnología, sellando un vínculo entre la educación y cultura que se mantuvo indisoluble hasta la creación - en 2013 - de la Secretaría de Cultura por los gobiernos neoliberales (Beristáin, 2018: 208).

Con la SEP en operación el conservatorio de música logró continuar sus actividades de educación artística dentro del seno de la Universidad Nacional hasta 1929, el año del conflicto de la autonomía universitaria. A esta etapa en específico del conservatorio me atrevo a denominarla como la del conservatorio universitario (1917-1929). Esta osadía se basa en la experiencia en la revisión del archivo histórico de la universidad y el mismo mote que la prensa de la época le asignaba a esta institución; pese a que el conservatorio cambió al nombre de Escuela de Música, Teatro y Danza, en los documentos oficiales - incluso en aquellos emitidos por la propia rectoría- continuó predominando el nombre de "Conservatorio de Música”. De esta manera podemos percatarnos que el legado del conservatorio siguió

\footnotetext{
${ }^{5}$ Para Bourdieu (1995: 222-223), la Escuela ocupa un lugar homónimo al de la Iglesia, "a través de la delimitación entre lo que merece ser transmitido y adquirido y lo que no lo merece, reproduce continuamente la distinción entre las obras consagradas y las obras legítimas y, también, entre la manera legítima y la manera ilegítima de considerar las obras legítimas".

${ }^{6}$ El Conservatorio Nacional de Música se fundó en 1866 como Conservatorio de la Sociedad Filarmónica, en una especie de reconocimiento de las élites a los músicos mexicanos por recrearlos de sus habilidades artísticas. En 1877 se expidió el decreto para su nacionalización. Las sociedades filarmónicas derivaron de las tertulias musicales, y "éstas fueron esenciales no sólo para el desarrollo y la propagación de la música, sino para el desarrollo de la cultura en general, pues constituyeron una de las formas de sociabilidad más importantes de la época" (Moreno, 2009: 25).

${ }^{7}$ Durante la dirección del conservatorio por el periodista y crítico musical Alfredo Bablot, en 1882 se organizó la Orquesta del Conservatorio Nacional. Ésta se integró por alumnos de la institución, así como de la orquesta de Santa Cecilia y de la Ópera. El objetivo de esta agrupación musical era contribuir al lucimiento de las fiestas nacionales. En 1992, bajo la batuta del maestro Carlos J. Meneses, la orquesta del conservatorio nacional recibió subvenciones por parte del Estado mexicano.
} 
presente en el imaginario de los músicos ahora en el nicho universitario. ${ }^{8}$

\section{Difusión del conservatorio y extensión universitaria}

Con el propósito de conseguir que los sectores de población que habían sido excluidos de toda acción cultural accedieran a conocimientos hasta entonces destinados al público universitario, José Vasconcelos y Antonio Caso impulsaron - en 1922- el funcionamiento del Departamento de Extensión Universitaria. La idea de la extensión universitaria no era nueva, se había propuesto desde los primeros años de la fundación de la universidad (1910-1912) por el consejero Miguel Martínez para poner en contacto a esta institución con su entorno. ${ }^{9}$ Una década después la propuesta se implementó, y el departamento se propuso ofrecer a los sectores de escasos recursos conocimientos técnicos y prácticos desde matemáticas hasta química, así como oficios manuales. Para esta ardua labor se contó con estudiantes, profesores universitarios - voluntarios o asalariados -, maestros de escuelas técnicas y de las normales. La extensión universitaria sólo se orientó a personas con estudios primarios, y abarcó desde conferencias, cursos por correspondencia, cursos de verano o invierno, y clases nocturnas (Alvarado, 2014: 134-136).

En el informe de las actividades de extensión universitaria desarrolladas entre 1926 y 1928, podemos encontrar datos relevantes sobre la participación del conservatorio universitario. Este informe se incluyó en la "Memoria" de los trabajos realizados por la universidad durante la administración del presidente Plutarco Elías Calles, y se distribuyó en marzo de 1929 entre todas sus facultades y escuelas (AHUNAM, FUN, sección DA, c. 30, exp. 851, fs. 12200-12293).

De acuerdo con el informe del departamento de extensión universitaria se contaba con un plan general de trabajo que repartía sus actividades en conferencias, ${ }^{10}$ difusión artística, difusión cultural por radio, infantil y cooperación social, así como en centros de extensión universitaria. En particular sobre la obra cultural desarrollada por extensión universitaria, este departamento concluye en su informe:

En concreto la obra de extensión universitaria ha sido realizar una amplia difusión de la cultura intelectual, moral, física y social. Por este motivo, mientras en el campo intelectual se está dando una oportunidad a nuestros hombres de ciencia de ponerse en contacto con personalidades que representan algunas de las más altas cumbres del pensamiento humano, dentro de su programa social llega hasta el desvalido para consolarlo y llevarle la buena nueva de que ella, la propia universidad, se preocupa por su bienestar; y se acerca a las fábricas y a los talleres; y alienta e ilumina a los obreros, a los trabajadores, sean del músculo o del cerebro y los acoge con amable solicitud. De este modo cumple su propósito de acercarse hasta el corazón del pueblo conmoviendo los cerebros y las conciencias (AHUNAM, FUN, sección DA, c. 30, exp. 851, fs. 12290-12291).

\footnotetext{
${ }^{8}$ Recomiendo revisar los trabajos colectivos de María Esther Aguirre Lora, entre éstos sugiero "Preludio y Fuga. Historias trashumantes de la Escuela Nacional de Música de la UNAM" (2008), para una mejor caracterización en la etapa de fundación de esta institución.

${ }^{9}$ Para conocer más sobre el espacio público y la acción estudiantil de la Universidad Nacional es vital revisar el artículo de Alicia Ziccardi (2014) en su obra coordinada "El barrio universitario de la Revolución a la autonomía". El barrio universitario enmarca territorialmente la vida transcurrida de la universidad desde su creación hasta 1929, el año de su autonomía. Éste es el espacio que se define por lo que acontecía en sus planteles y también fuera de ellos. Como señala Marsiske (2019: 432), en este barrio no sólo se encontraban los edificios de la Universidad Nacional, sino también las oficinas del gobierno, así como teatros, cafés, casas de huéspedes; en una ciudad remodelada por Porfirio Díaz para las celebraciones del Centenario de la Independencia en 1910... una ciudad que se había empezado a modernizar.

${ }^{10}$ En la sección de conferencias se impartieron temas sobre sociología, economía política, psicología, historia y civismo, higiene, literatura y diversos temas científicos.
} 
La identidad de los profesores y estudiantes del conservatorio universitario poco a poco se fue fortaleciendo a través de un conjunto de propiedades establecidas en su campo artístico; entre éstas es indispensable destacar la de "pertenencia", la cual incluye desde los nombramientos, reconocimientos, reglamentos, subvenciones económicas hasta la difusión. En este sentido la organización y proyección de la orquesta de alumnos del conservatorio y la agrupación universitaria de música de cámara ${ }^{11}$ siempre contó con el respaldo de la Rectoría y del Departamento de Extensión Universitaria. Tan solo en el mes de diciembre de 1928, de 21 eventos culturales que se presentaron en el Anfiteatro de la Escuela Nacional Preparatoria, siete fueron realizados por extensión universitaria y el conservatorio (AHUNAM, FUN, sección DA, c. 23, exp. 635, f. 09564). Por otra parte, la subvención económica que recibían los integrantes de ambas agrupaciones, además de ser uno de los elementos de pertenencia del conservatorio universitario, era una pequeña ayuda

Imagen 1. Carlos J. Meneses

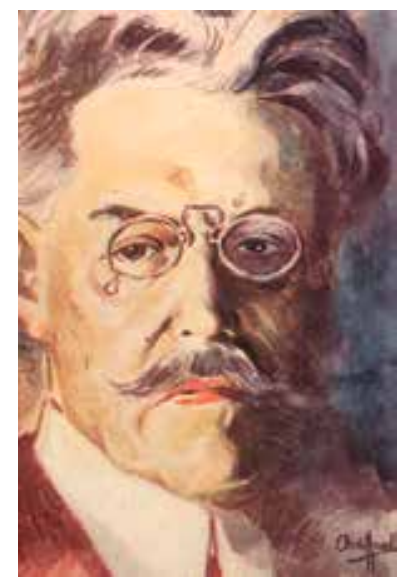

Fuente: Hemeroteca Nacional de México, Ilustrado del diario El Universal, 23 de abril, 1929 para accesorios o reparaciones leves de sus instrumentos, gastos de transporte y otros usos.

El extensionismo realizado desde la Universidad Nacional, a partir de Vasconcelos como su rector, fue el instrumento principal por el que ésta y los universitarios participaron de la tarea educativa, asumida como revolucionaria, deber patriótico y moral (Cano, 2019: 99). ${ }^{12}$ Los alumnos y profesores del conservatorio universitario realizaron sus actividades acordes a los planes de trabajo de la extensión universitaria, la que estaba en sincronía con el proyecto educativo de los gobiernos posrevolucionarios; en particular en el periodo 1924-1928, bajo la presidencia de Plutarco Elías Calles y el rectorado de Alfonso Pruneda, quien impulsó una de las más fuertes transformaciones administrativas, académicas y de extensión. El conservatorio universitario contribuyó al proyecto del gobierno posrevolucionario de Calles con una serie de conciertos destinados a niños y obreros, didácticos e históricos, así como también estimuló la producción musical de compositores mexicanos.

\section{Imagen 2. Invitación al primer concierto del conservatorio universitario en conmemoración del Centenario de la muerte de Beethoven}

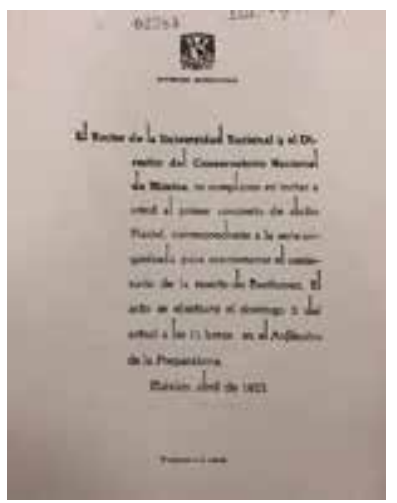

Fuente: AHUNAM, FUN, sección DA, c. 8, exp. 164, f. 03988.

\footnotetext{
${ }^{11}$ Esta agrupación era dirigida por el célebre músico Carlos J. Meneses, quien había dirigido la antigua orquesta del conservatorio nacional, y que también transmitió su legado musical a sus discípulos como el virtuoso pianista Pedro Ogazón, Alba Herrera y Ogazón y Carlos del Castillo, entre otros. Era tan fuerte la trayectoria del Carlos J. Meneses en el campo artístico del conservatorio universitario que la agrupación de cámara se anunciaba como la del "maestro Meneses", obligando a la rectoría a emitir el "Acuerdo 3" — en enero de 1926 - para que en cada presentación dicha agrupación se anunciara como la "Agrupación Universitaria de Música de Cámara". Esto fue una clara muestra de las disputas al interior del campo de los músicos, entre los que dejan un legado, aquellos que ingresan y los propios mecanismos de la institución. ${ }^{12}$ Para conocer un poco más sobre los momentos nodales del extensionismo universitario es muy recomendable revisar el trabajo de Agustín Cano Menoni (2019) en "Cultura, nación y pueblo. La extensión universitaria en la UNAM (1910-2015)". La obra focaliza la problemática de la extensión a partir de siete momentos de su proceso histórico: fundacional, originario, institucionalización, politización, despolitización y resignificación.
} 


\section{Autonomía universitaria y su impacto en el conservatorio universitario (1929)}

En diciembre de 1928, el músico y compositor Carlos Chávez fue designado director de la Escuela de Música, Teatro y Danza, ${ }^{13}$ también conocida como conservatorio universitario. Desde un principio, como apunta la biógrafa Gloria Carmona (1997: xiv-xv), la oposición de los decanos de la institución se declaró abierta desde entonces ante un Chávez que situaba a la actividad artística en la categoría de asunto de Estado. Las iniciativas de Chávez durante su gestión en los siguientes meses fueron ensombrecidas por el movimiento estudiantil de "autonomía". ${ }^{14}$

\section{Imagen 3. Gloria Carmona, pianista y biógrafa del maestro Carlos Chávez}

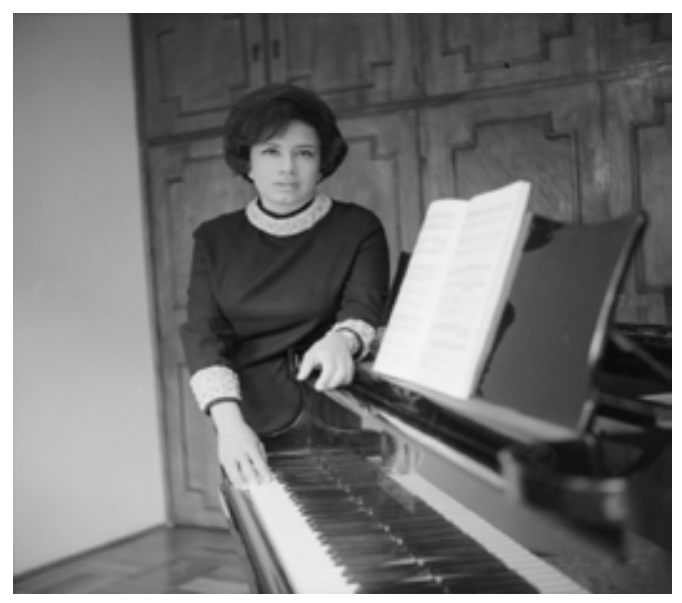

Fuente: IISUE/AHUNAM/Colección Ricardo Salazar Ahumada/RSA-001368
Escudriñando en los fondos del AHUNAM, pude llegar hasta una serie de documentos inéditos que comprueban el intento del maestro Chávez para consolidar una orquesta sinfónica de carácter nacional y representativa en el seno de la universidad; una iniciativa que probablemente pudo no haber logrado mayores adeptos entre los profesores músicos universitarios pero que sí logró contar con el respaldo del gobierno local y federal, rectoría y la secretaría de educación pública; esta última estaba presidida por el licenciado Ezequiel Padilla.

El 28 de enero de 1929, José Manuel Puig Causaranc, jefe del Departamento del Distrito Federal, concedió una "subvención" de $\$ 1,666.00$ mensuales, para todo el presente año, destinada a la Orquesta Sinfónica de México $(\mathrm{OSM})^{15}$ que ahora dependería de la Universidad Nacional. Este cargo se realizó a través de la partida global de acción educativa, de reforma, recreativa y social de dicho departamento (AHUNAM, FUN, sección DA, c. 42, exp. 1308, fs. 15696-15697). Tres meses después, Antonio Castro, rector de la Universidad Nacional, envió las bases para el funcionamiento ${ }^{16}$ de esta orquesta a Moisés Sanz, subsecretario de educación pública:

Adjuntas se servirá usted encontrar las bases que para el funcionamiento de la Orquesta Sinfónica de México ha redactado la Rectoría de la Universidad

\footnotetext{
${ }^{13}$ El 18 de marzo de 1929, la rectoría de la Universidad Nacional dio a conocer al maestro Chávez el "Acuerdo" sobre el reglamento de esta escuela, en el cual se especifica que además de la dirección se tendría que encargar de la actividad técnica de la sección musical, mientras que las secciones de teatro y danza serían designadas por la rectoría a otros profesores, que el propio Chávez propusiera (AHUNAM, FUN, sección DA, c. 31, exp. 902, f. 12609).

${ }^{14}$ Coincido con investigadores como Miguel Angel Gutiérrez López (2018: 50) en el sentido de la dificultad para establecer una definición única de "autonomía", pues ésta adquiere ciertas particularidades de acuerdo con su momento histórico, y así sucedió en el caso de la Universidad Nacional. Las definiciones pueden fluctuar entre aquellas que contemplan la facultad de las universidades para gobernarse, el espacio entre el presupuesto federal y la libre decisión de la universidad para ejercerlo, hasta la voluntad de la comunidad universitaria para participar en la vida pública, entre otras. En el caso específico de los músicos del conservatorio universitario, éstos estaban convencidos de que la inserción de "intereses políticos" y el "personalismo" de los directivos aniquilaban las mejores iniciativas en beneficio de la educación artística.

${ }^{15}$ Carlos Chávez fue invitado en 1928 por el Sindicato de Filarmónicos del Distrito Federal para reorganizar la Orquesta Sinfónica Mexicana, agrupación propia del organismo, en plena crisis del cine mudo ante el sonoro y en donde proliferaban músicos ejecutantes del género del jazz. Chávez cambió el nombre de esta agrupación por el de Orquesta Sinfónica de México (OSM), y la hizo funcionar bajo el modelo de un patronato privado y el subsidio del Estado a través de la SEP.

${ }^{16}$ Estas bases también fueron dadas a conocer a las siguientes personalidades: Luis Montes de Oca, secretario de Hacienda y Crédito Público; Genaro Estrada, subsecretario de Relaciones Exteriores; Antonieta Rivas Mercado, Hortensia Calles de Torreblanca, Margarita C. de Sáenz; Carlos Chávez, director de la Orquesta Sinfónica de México, y de la Escuela de Música, Teatro y Danza; Sra. de Dwigth W. Morrow, entre otros.
} 
Nacional. De acuerdo con el artículo $4^{\circ}$ de las bases, serán miembros del Consejo de la que fue Orquesta Sinfónica Mexicana a quienes el Rector de la Universidad ratifique su nombramiento por medio de una invitación. Tendría un gran placer en que la Orquesta Sinfónica de México pudiera contar con la entusiasta y desinteresada cooperación con que se ha servido usted ayudarla (AHUNAM, FUN, sección DA, c. 42, exp. 1308, f. 15698).

Detrás de esta iniciativa, ¿cómo funcionaría esta agrupación musical que tenía su origen fuera de la universidad, y de qué manera integraría a profesores y alumnos del conservatorio universitario? Para una respuesta más clara, lo mejor es revisar y analizar los primeros nueve puntos de las bases propuestas para su funcionamiento:

1. Bajo los auspicios de la Universidad de México se forma una agrupación musical que se llamará Orquesta Sinfónica de México. 2. La orquesta sinfónica de México la formarán un director, un subdirector y, cuando menos, cien ejecutantes de los cuáles uno tendrá el carácter de violín concertino y otro el de jefe de alientos. Además, contará con un secretario, un representante general, un contador, un encargado del instrumental y un mozo. 3. El rector de la Universidad Nacional nombrará al director de la orquesta y de acuerdo con éste, a los ejecutantes y empleados administrativos. 4. El gobierno de la orquesta estará a cargo de un consejo consultivo y de un consejo ejecutivo. El primero estará formado, por derecho propio, por el secretario de Educación Pública, quien lo presidirá, el jefe del Departamento del Distrito Federal y el rector de la Universidad Nacional y, además, como informadores, los miembros del consejo de la que fue la Orquesta Sinfónica Mexicana a quienes el rector rectifique su nombramiento por medio de una invitación y a los nuevos que él designe. El consejo ejecutivo estará formado por el rector de la universidad y el director de la orquesta. 5. Estará a cargo del consejo consultivo: a) reunir los fondos necesarios para el sostenimiento de la orquesta, b) aceptar o no los donativos condicionales de instituciones o de particulares; c) determinar los actos públicos en que la orquesta pueda tomar participación; d) aprobar el informe anual que le rinda el consejo ejecutivo; e) las demás facultades que le den estas bases. 6. Estará a cargo del consejo ejecutivo: a) determinar el número de conciertos y las fechas en que deban darse, tanto dentro de la temporada como fuera de ella; b) administrar los recursos destinados al sostenimiento de la orquesta; c) aceptar los donativos incondicionales de instituciones o de particulares; d) ejecutar los acuerdos del consejo consultivo. Al director de la orquesta se reserva la elección de obras y la formación de programas, correspondiéndole también la vigilancia y disciplina de la orquesta. 7. La orquesta contará para su sostenimiento: a) con asignaciones que de sus fondos propios señale la Universidad Nacional; b) con las asignaciones que se consignen en los presupuestos del gobierno federal; c) con los donativos de instituciones oficiales y privadas y de particulares; d) con el producto de los conciertos. Los fondos que se reúnan para los conceptos a y b se destinarán al pago de sueldos del director y personal de la orquesta hasta el punto en que estos sean necesarios. El exceso, si lo hay, y los fondos reunidos con los donativos de los particulares o con el producto de los conciertos, se destinarán al desarrollo de la orquesta y al mejoramiento de sus componentes, de acuerdo con el plan de distribución que apruebe el consejo consultivo. 8. El director de la orquesta someterá al rector de la universidad, para su aprobación, un reglamento interior de la orquesta. 9. Los profesores y alumnos graduados de la Escuela de Música, Teatro y Danza serán preferidos, en igualdad de circunstancia, para ocupar en la orquesta las plazas de ejecutantes que queden vacantes (AHUNAM, FUN, sección DA, c. 42, exp. 1308, fs. 15711-15713). 


\section{Imagen 4. Carlos Chávez}

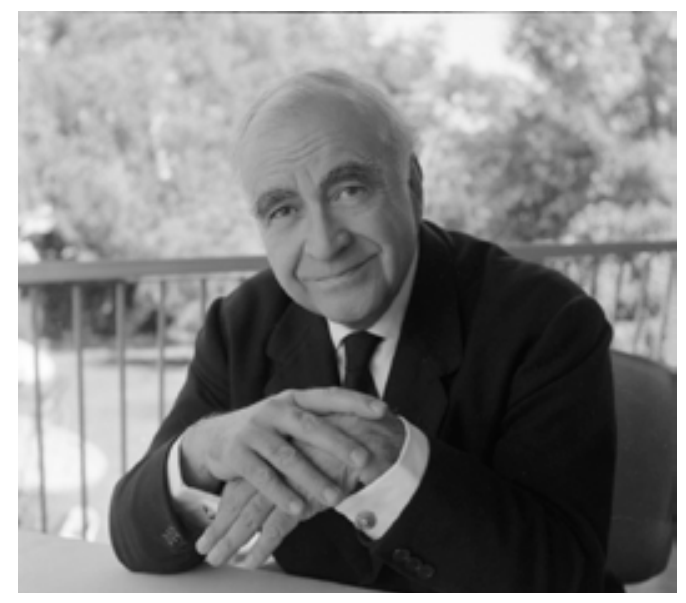

Fuente: IISUE/AHUNAM/Colección Ricardo Salazar Ahumada/RSA-001675.

En estas bases de funcionamiento se puede entrever que la orquesta sinfónica de México, ahora bajo el cobijo de la Universidad Nacional, contaría con un mecanismo de asesoramiento (consejo consultivo) dependiente de la SEP, del Departamento del Distrito Federal y la Rectoría; y, por otro lado, de un mecanismo de dirección (consejo ejecutivo) bajo el mando del rector y del director de la orquesta, quedando al margen del proyecto la propia dirección del conservatorio universitario. El proyecto de la OSM en la universidad contemplaba una temporada anual de seis conciertos que incluían obras y solistas mexicanos, y en donde para la propia universidad se reservaba el uso de las localidades de segundos y galería para que asistieran obreros y niños de escuela (ibid., f. 15726); sin embargo, este tipo de "contradicciones" en los proyectos de educación artística en la universidad, así como la injerencia de gobiernos locales y federales, fueron duramente cuestionadas durante el proceso del conflicto de autonomía por los músicos universitarios "disidentes", de aquellos que lucharon por su dignificación cultural.

¿Cuáles fueron los eventos que se suscitaron durante el conflicto de autonomía que provocaron la reunión de un grupo de profesores y alumnos de música inconformes ante la segregación del conservatorio de la universidad? Primero hay que recapitular el conflicto y, posteriormente, la segregación de los músicos universitarios. En abril de 1929, el rector Antonio Castro Leal declaró ante diarios capitalinos la necesidad urgente de fijar un sistema adecuado para mejorar la valoración del aprovechamiento de los alumnos, en particular de los de Derecho y Ciencias Sociales. Esto porque estaba pendiente la puesta en práctica, desde 1925, de un sistema de reconocimientos trimestrales aprobados por el Consejo Universitario, Rectoría y la SEP, los cuales se venían posponiendo por distintas circunstancias. El 5 de mayo, los estudiantes se posesionaron del edificio de la Facultad de Derecho, desplegaron la bandera rojinegra y el escudo de la Federación Nacional de Estudiantes, y al día siguiente impidieron el paso a quienes querían tomar cursos y silbaron al rector cuando se disponía a dar clases (Marsiske, 2016: 175). Para el 7 de mayo, a través de la prensa, Arcadio D. Guevara y Antonio D'Amiano - presidente y secretario de la sociedad de alumnos de la Escuela de Jurisprudencia-, en oposición al establecimiento del sistema de reconocimientos, informaron la declaración de huelga. Castro Leal nunca concordó con la postura de suprimir un acuerdo del Consejo Universitario, y para el 13 de mayo, editoriales de diarios como El Universal criticaron la decisión del presidente del país de clausurar la Escuela de Jurisprudencia. Para el mandatario Emilio Portes Gil, la huelga era injustificada y una muestra de franca indisciplina, y estaba dispuesto a castigar con energía cualquier delito o alteración del orden. El 23 de mayo se suscitó un zafarrancho en la Escuela de Derecho, entre estudiantes y bomberos; José Manuel Puig Causaranc - jefe del Departamento del Distrito Federal - logró evitar derramamiento de sangre y se propuso intervenir ante el presidente del país. Alejandro Gómez Arias - presidente del directorio de la huelga y de la Confederación Nacional de Estudiantes-, como respuesta a estos actos, envió una carta a Causauranc en donde reafirmaba la 
convicción que tenían los universitarios: la de un Estado que buscaba resolver con violencia un conflicto meramente universitario (Gaceta UNAM, 2001: III).

Finalmente, el gobierno retiró las fuerzas policiales y de los bomberos que custodiaban los edificios escolares, encomendando a los estudiantes el orden de los edificios y la guarda de los muebles. El 25 de mayo fue un día clave para los estudiantes, entre proposiciones de renuncias de funcionarios y otros aspectos, Gómez Arias, en su discurso en la Facultad de Medicina, fue contundente al señalar que el verdadero motivo de la huelga no fue el asunto de los reconocimientos para los estudiantes de leyes, sino que el Consejo Universitario no estuviera conformado de manera proporcional por maestros y alumnos, y que en su seno se resolvieran todos los conflictos universitarios. Los estudiantes querían ser escuchados, y si no estaban en lo justo que se les demostrará lo contrario, pero no por la vía de la fuerza. A partir de ese momento el reclamo se convirtió en la exigencia del gobierno autónomo de la universidad (Gaceta UNAM, 2001: IV). El 10 de julio de 1929 se promulgó la Ley Orgánica de la Universidad Nacional de México, Autónoma; y dos días después, Gómez Arias dio por concluida una huelga que duró 68 días. Para Marsiske (2016: 182-185) esta ley de autonomía quedaba lejos de dar una estructura moderna a la universidad, pero era el reflejo de un proyecto de universidad para el futuro de México; además se trataba de una autonomía incompleta, pese a que la máxima autoridad recaía en el Consejo Universitario (integrado por el rector, el secretario de la Universidad y los directores de las facultades), el presidente de la República se reservaba el derecho de presentar una terna al consejo para el nombramiento del rector, el cual tendría que provenir del sector gubernamental y no del seno universitario. La ley de autonomía de la universidad por ende dejó fuera a la Orquesta Sinfónica de México; de esta manera el proyecto de Chávez tendría una vida efímera en el seno de esta institución:
México, D.F., a 14 de octubre de 1929. Al C. Rector de la Universidad Nacional. Presente. Según la ley de 10 de julio del presente año por la que se concede su autonomía a la Universidad Nacional de México ésta pierde la posesión del Estadio Nacional y de la Orquesta Sinfónica de México. Como aún se siguen sosteniendo tanto el estadio como a la orquesta por cuenta de esta universidad sin que legalmente le corresponda, ocasionando con ello un gasto de varios miles de pesos [...] Pongo en el conocimiento de usted lo anterior para los fines que crea usted pertinente. Reitero a usted mi atenta consideración. El auditor. Alfredo F. Gutiérrez (AHUNAM, FUN, sección DA, c.34, exp. 989, f. 13492).

\section{Músicos universitarios "segregados" en pos de una facultad de música}

Con la publicación de la ley de la Universidad y su autonomía quedó excluido el conservatorio, también denominado Escuela de Música, Teatro y Danza. Alejandro Gómez Arias calificó como un acto de sorpresa contra los estudiantes su "segregación", culpando principalmente a Carlos Chávez, quien finalmente logró su cometido de integrar esta institución ahora en el seno de la SEP. El descontento e indignación de los profesores y estudiantes universitarios disidentes al maestro Chávez no se hizo esperar, y a través de una serie de reuniones de asamblea estos elementos iniciaron los trabajos de la proyección de una nueva escuela universitaria de música. En el campo de estos músicos universitarios las sesiones ordinarias y extraordinarias de estas asambleas se convirtieron en los lugares comunes donde se debatieron sus problemas comunes, pero ahora para abonar terreno fértil a un nuevo proyecto.

Las profesoras Alba Herrera y Ogazón y María Caso, integrantes de la comisión para redactar una "Breve historia de los hechos relativos a la fundación de la Facultad de Música" (AHUNAM, ENM, c. 14, exp. 5, fs. 4910-4946), destacaron las sesiones ( $3^{\mathrm{a}} \mathrm{y}$ $4^{\text {a }}$ ) del 15 de julio como clave en los comienzos de un 
nuevo conservatorio universitario, nombrándose comisiones como las de propaganda y, principalmente, una que se acercara al rector de la universidad con el objetivo de promover la creación de este proyecto.

En la $3^{\text {a }}$ sesión realizada por la mañana en el anfiteatro Bolívar de la Escuela Nacional Preparatoria, en asamblea presidida por la profesora Herrera y Ogazón, se integró una comisión de cuatro profesores y cuatro alumnos ${ }^{17}$ para entrevistarse con el rector para pedirle la adhesión de una nueva escuela de música (AHUNAM, ENM, c. 14, exp. 3, fs. 48974898). Por la tarde, durante la $4^{\mathrm{a}}$ sesión desarrollada en el salón Justo Sierra de la Escuela Nacional Preparatoria, el maestro Estanislao Mejía informó a los asistentes y la prensa que la comisión fue acogida con benevolencia por parte del rector de la universidad, y que existía la disposición de poner parte en ayudar a la causa de los músicos segregados; pero que se deseaba conocer todos los puntos de vista, planes de estudio, entre otros aspectos. En esta asamblea, la petición del estudiante Pascual Hernández de que mediante firma se comprometan los asistentes a "no volver a clases al conservatorio" se hizo realidad: "Los alumnos suscritos nos comprometemos a no pisar la escuela de música, teatro y danza, mientras el asunto de que dicho plantel esté en trámite; una vez transmitidas las gestiones que tienden a este fin, cada uno queda en libertad de obrar" (AHUNAM, ENM, c. 14, exp. 3, fs.4898-4899).

En esa misma reunión se dio lectura al Plan de Estudios que estaba en vigor desde 1928, y se propuso reformar el artículo segundo, en donde en lugar de Declamación debía figurar el Arte Teatral, así como algunos cambios en otros considerandos. Cabe recordar que el proyecto de Plan de Estudios de 1928 fue presentado para su aprobación profesional en el mes de enero de ese año; sin embargo, fue finalmente aprobado hasta el 7 de febrero de 1929, cuando el maestro Carlos Chávez ya fungía como director del conservatorio universitario. Los planteamientos expuestos durante los congresos nacionales de música de 1926 y 1928, sirvieron de base para este plan de estudios, el cual se propuso fortalecer la educación integral de los músicos, el estudio del folklore y el fomento de la música mexicana, así como ampliar las exigencias y pruebas al final de la carrera (Zanolli, 2017: 323-327)

En la $5^{\text {a }}$ sesión extraordinaria del 16 de julio se conformaron comisiones para acudir a academias de música y hacer propaganda a favor del nuevo proyecto de escuela de música; así como difundir su finalidad ante la prensa. La 6 a sesión extraordinaria del 20 de julio contó con un quorum de cinco maestros y 70 alumnos, siendo presidida por el profesor Estanislao Mejía, y se reiteró el apoyo que el rector mostraba a la causa, así como su aprobación hacia Alejandro Gómez Arias, ${ }^{18}$ quien era candidato viable para formar parte del nuevo consejo universitario, y también uno de los que primeramente ofrecieron su respaldo para la formación de una nueva escuela de música en la universidad (AHUNAM, ENM, c. 14, exp. 3, fs. 4900-4903).

Entre el 15 y 29 de julio, a través de varias asambleas, se llevaron a cabo todas las gestiones con relación a las entrevistas con el rector Ignacio García Téllez para fundamentar el proyecto de creación de una nueva escuela musical universitaria. Entre los puntos del memorial que se redactaron en la comisión de profesores para esta misión destacan los siguientes considerandos:

\footnotetext{
${ }^{17}$ Alba Herrera y Ogazón, Elena Otero y Gama, David F. España; y los alumnos: Carmen Peñaloza, Carmen Bretón, Carlos Quiroz y Manuel C. Asencio.

${ }^{18}$ Gómez Arias se caracterizó por ser un gran erudito y orador, y principalmente por fungir como presidente de la Comisión de Huelga en el movimiento de la autonomía universitaria, inspirado en los ideales de Justo Sierra en cuanto al carácter nacional y el compromiso social.
} 
$1^{\circ}$. La integridad de la Universidad Autónoma exige un Departamento Musical en su seno, departamento de índole profesional, es decir, Escuela en la cual se cursen carreras específicas cuya legalidad quede acreditada por un título profesional [...] 2 . La única solución del conflicto conservatoriano consiste en crear la Escuela propuesta que satisfará plenamente las aspiraciones más altas del arte en México. De esta manera, la universidad quedará integrada y apta para desarrollar ampliamente su labor cultural y de acercamiento al pueblo por el medio de mayor efectividad, la música en sus diversas manifestaciones. $3^{\circ}$. Una Escuela de la importancia indicada debe estar a salvo de cambios políticos y crisis ministeriales si ha de cumplir la misión trascendental que le corresponde. $4^{\circ}$. El conflicto imprevisto de la desmembración universitaria motivada por la segregación infundada del conservatorio, ha perjudicado gravemente a un enorme grupo de estudiantes, sembrando la desmoralización entre la juventud artística y violando derechos conquistados con ímprobos trabajos. $5^{\circ}$. La fundación de la Escuela de Música no presenta problema alguno de orden económico puesto que dicha escuela, podrá crearse, por el momento, como un departamento anexo [...] a Filosofía y Letras. Además, algunos de los profesores subscritos están dispuestos a impartir la instrucción gratuitamente durante el tiempo que sea necesario (AHUNAM, ENM, c. 14, exp. 5, fs.4920-4922).

Los profesores segregados presentaron formalmente su renuncia, el 23 de julio, como una manera de rompimiento de toda liga con el conservatorio, y de cierta manera darle mayor legitimidad y resonancia a su movimiento:

Señor Director de la Escuela de Música, Teatro y Danza. Presente. Los suscritos profesores de la Escuela de Música, Teatro y Danza, tenemos el honor de presentar a usted nuestra renuncia conjunta a los cargos que hemos venido desempeñando en el referido plantel, algunos firmantes durante muchos años consecutivos. Los motivos que nos han impulsado a tomar esta resolución son los siguientes: la segregación del ex-conservatorio de música del seno de la universidad, propuesta y llevada a cabo sin tomar en cuenta, no ya las más altas finalidades para que existiera dicha escuela, sino los derechos perfectamente ganados de profesores y alumnos, ha provocado profundo descontento entre aquellos estudiantes conservatorianos que tienen nobles aspiraciones con relación a su carrera y al porvenir artístico de nuestro país. Esta inconformidad muy justificada, a nuestro juicio nos ha puesto en presencia de uno de los más sagrados deberes del maestro: llegar al sacrificio, si es preciso, con tal de no desvirtuar o malograr en la conciencia juvenil, los impulsos generosos y levantados que son garantía inestimable para el futuro de la patria.

Creemos cumplir nuestra misión de educadores honrados al tomar como nuestros los intereses legítimos de los educandos y desligarlos de condiciones que a ellos consideramos nocivas. Rogamos a usted, por lo tanto, se sirva aceptar la renuncia de los empleos que hemos desempeñado, fieles siempre, a un ideal de mejoramiento y progreso por cuya realización continuaremos luchando como hasta aquí (...) Estanislao Mejía, Alba Herrera y Ogazón, Fausto Gaitán, María Caso, Agustín C. Beltrán, José F. Vázquez, Dolores Pedrozo, Humberto Macías Campos, Carlos Santos, Miguel C. Meza (AHUNAM, ENM, c. 14, exp. 5, fs.4923-4924).

Otras voces apoyaron la causa de los músicos segregados, como sucedió en el caso de Pedro de Alba, quien en ese momento era director de la Escuela Nacional Preparatoria y, posteriormente, presidente del Instituto Panamericano de Cooperación Intelectual, con sede en Washington:

En la Secretaría de Educación Pública las actividades artísticas tienen una orientación divulgadora y 
popular; en la universidad se trata de discutirlas en un plan superior de la cultura. Que siga la Secretaría de Educación Pública cultivando el campo de la sensibilidad musical de nuestro pueblo; pero la universidad tiene que elevar el tono y el estilo para cimentar la Escuela Mexicana de Música [...] La universidad necesita de los músicos y los músicos del ambiente universitario. Se dice frecuentemente que tenemos muy buenos músicos, pero que carecen de una ilustración media que los capacita para superarse y desarrollar todas sus posibilidades. Esto no es una regla absoluta, pues hay entre los músicos profesionales un grupo de maestros muy bien preparados, que tienen derecho a ocupar un lugar en el mundo universitario y que estarán dispuestos a llevar su contingente a la nueva institución (AHUNAM, ENM, c. 14 , exp. 7, fs. 4955-4956).

Finalmente, el Consejo Universitario aprobó la creación del centro musical proyectado por los músicos segregados. El profesor Luis G. Saloma, entonces director de este recinto, narraría este suceso - en una misiva enviada en diciembre de 1944 a la oficina de cooperación intelectual de la unión panamericana- de la siguiente manera:

Y así fue como con fecha 7 de agosto de 1929, el Consejo Universitario votó por unanimidad y sin discusión, la creación de la Facultad de Música, siendo rector el Lic. García Téllez, y secretario el Lic. José López Lira. Al esfuerzo e interés de estos dos funcionarios debemos sumar los de los señores consejeros Dr. Antonio Caso, director de la Facultad de Filosofía y Letras; Dr. Pedro de Alba, director de la Escuela Nacional Preparatoria; Lic. Julio Jiménez Rueda, director de la Escuela de Verano y otros muchos, así como distinguidos estudiantes como el Sr. Alejandro Gómez Arias de la Escuela de Leyes cuya eficaz y generosa ayuda conjunta fue de gran trascendencia para el establecimiento del nuevo plantel. El propio H. Consejo designó a una comisión para que estudiara todo lo relacionado con la marcha y funcionamiento de la nueva escuela, la cual estuvo formada por consejeros profesores y alumnos, así como por maestros y alumnos distinguidos del plantel. Después del dictamen correspondiente presentado por esta comisión y que fue favorable, la Universidad Nacional Autónoma de México ordenó que se abrieran las inscripciones en el nuevo conservatorio universitario con fecha 23 de agosto. El plan de estudios a que debía sujetarse quedó terminado entre los días 23 y 25 del propio mes. Días después del H. Consejo Universitario ascendió de categoría al plantel con el nombre de Facultad de Música.

El día 7 de octubre de 1929 se llevó a cabo la solemne inauguración siendo su primer director el maestro Estanislao Mejía, que tuvo a su cargo el discurso oficial. La declaratoria de reglamento de apertura fue hecha por el Sr. Rector de la Universidad Nacional Autónoma, Lic. Ignacio García Téllez. A partir de esta fecha tanto profesores como alumnos redoblaron sus esfuerzos trabajando horas extras a fin de recuperar el tiempo perdido; las clases se prolongaron hasta el periodo de vacaciones y fue así como los exámenes pudieron efectuarse en el mes de febrero del siguiente año. Los profesores dieron prueba de cariño y desinterés por su escuela, y que sirvieron sus cátedras sin remuneración alguna desde la apertura hasta el primero de enero de 1930, en cuya fecha les fueron extendidos los nombramientos respectivos. Los mismos contribuyeron después pecuniariamente para sostener una Orquesta Sinfónica que presentó interesantes conciertos con halagadores éxitos, tratando así de conservar el prestigio artístico del plantel. La creación por tanto de la Facultad de Música constituye una de las obras iniciales de la Universidad Nacional Autónoma de México y es manifestación primísima de su voluntad creadora. El plantel está identificado plenamente con ella y siente repercutir el pulso de su existencia espiritual (AHUNAM, ENM, c. 14, exp. 8, fs. 4961-4962). 
Para diciembre de 1929, el maestro Estanislao Mejía, director de la recién creada Facultad de Música, comunicó a la Rectoría de la Universidad quienes serían los integrantes de la "Academia", así como los representantes de ésta ante el honorable Consejo Universitario:

[...] en sesión extraordinaria efectuada en esta facultad el viernes 13 del presente, se hizo la designación de profesores que habrán de integrar la Academia respectiva, así como los representantes de esta facultad ante el H. Consejo Universitario. Fueron electos consejeros representantes de esta facultad los profesores srita. Alba Herrera y Ogazón y Sr. Manuel Barajas, como propietarios y Srita. María Caso y Sr. José F. Vázquez como suplentes. La Academia de Profesores quedó integrada por los señores profesores Pedro Michaca, José F. Vázquez, Sra. Dolores Pedrozo y Srita. Alba Herrera y Ogazón, Sres. José Rocabruna, Humberto M. Campos, Ramón Hernández, Julio Jiménez Rueda, Srita. María Caso y Sr. Melquiades Campos" (AHUNAM, FUN, sección DA, c. 28, exp. 1, f. 10408).

Años después, el profesor Estanislao Mejía, ${ }^{19}$ en su artículo "En el aniversario de la Escuela de Música de la Universidad" (Ilustrado, 20/X/1938), ante posturas de músicos extranjeros acerca de la cultura musical como parte esencial de la educación, resaltó el espíritu de la autonomía universitaria, sus músicos disidentes, el papel del consejo universitario y su repercusión en la dignificación cultural del músico mexicano:
Imagen 5. Estanislao Mejía, director de la Facultad de Música (centro arriba); Margarita Ochoa Mondragón (izquierda arriba), David F. España (derecha arriba), Ernesto Enríquez (izquierda centro), y Jesús Haro Tamariz (derecha centro), consejeros de la Facultad de Música

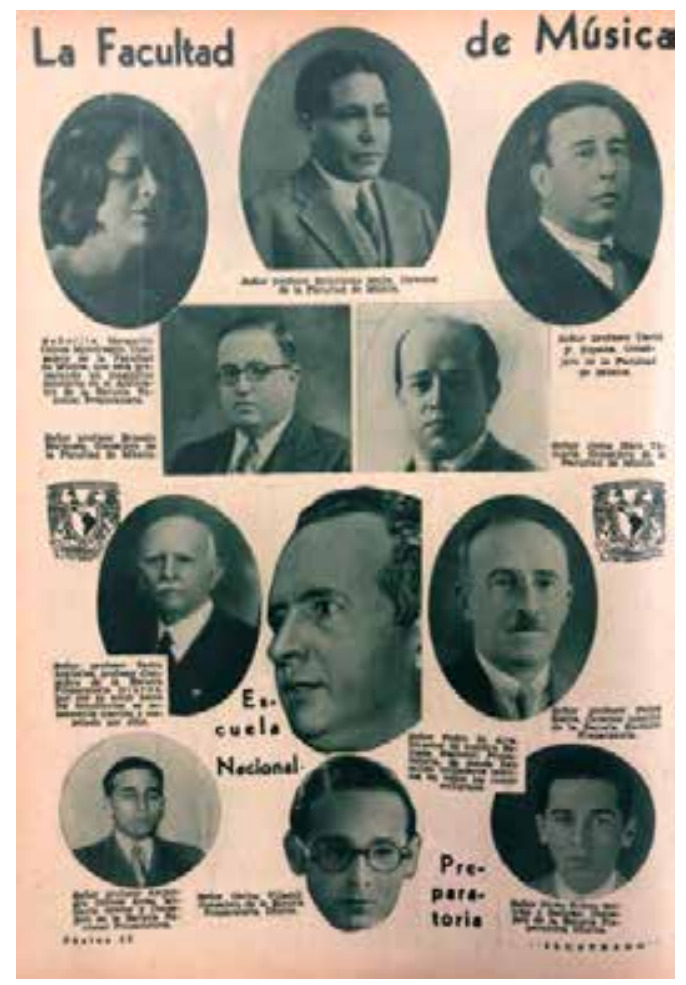

Fuente: Hemeroteca Nacional de México, llustrado del diario El Universal, 18 de agosto, 1932.

\footnotetext{
${ }^{19}$ El profesor Estanislao Mejía dirigió la Facultad de Música de la Universidad a partir del 7 de septiembre de 1929 hasta el 13 de octubre de 1933, bajo los rectorados del abogado Ignacio García Téllez y del ingeniero químico Roberto Medellín; el profesor José Rocabruna lo sustituyó el 14 de octubre de ese último año hasta el 15 de julio de 1942, bajo los rectorados del abogado Manuel Gómez Morín, del doctor Enrique C. Aragón, del médico cirujano Fernando Ocaranza, del abogado Luis Chico Goerne, del médico cirujano Gustavo Baz, y de los abogados Mario de la Cueva y Rodolfo Brito Fucher (AHUNAM, ENM, c. 14, exp. 12, f. 5039).
} 
Basta citar los conceptos transcritos para formarse una idea de la actitud de un grupo de profesores y estudiantes del Conservatorio en mayo de 1929, los que, formando una fuerza de solidaridad, se propusieron reincorporar la Escuela de Música a la Universidad Autónoma de México. Se hablaba entre aquellos "disidentes" de la dignificación cultural del músico mexicano. Se hablaba de los problemas de orden estético, artístico, educativo, social, administrativo. Se pretendía corregir la labor desordenada, interrumpida y nulificada por los vaivenes de la política, así como al funesto personalismo, que aniquilan toda iniciativa tendiente a un bien común.

Obligado aquel grupo a hacer frente a las circunstancias creadas con motivo de la autonomía concedida a la Universidad, empezaba a sentirse estimulado por el Comité de Alumnos Universitarios que era a la vez, el germen de la autonomía. Ante la seriedad de las circunstancias creadas por el romanticismo de nuestros ideales de mejoramiento musical, discutíamos en las aulas de la Preparatoria, las medidas que se deberían tomar, desdeñando los insultos de los interesados y las frías advertencias de los calculadores; y, perdiendo el sentido de inevitables dificultades en los arranques sinceros de algunos de nuestro grupo, el Consejo Universitario, consciente de lo que sin distinción de credos alumbra a las masas, reincorporó a la Universidad Autónoma el día 7 de octubre de 1929, su Centro de Educación Musical, que desde el triunfo de la Revolución le había sido adherido, pero por circunstancias políticas le fue cercenado en el mismo año 29.

\section{Los difíciles años treinta}

En esta década, México tuvo que enfrentar los efectos de la crisis económica provocados por la Gran Depresión. Al final de ésta, Estados Unidos y Canadá no lograron recuperar sus niveles del Producto Interno Bruto (PIB) anteriores a la recesión mundial, mientras que en América Latina esta depresión logró acelerar una serie de procesos que fueron más allá del impacto económico (Drinot, 2015: 15). Cabe recordar que la gran depresión de 1929 tuvo como epicentro a Estados Unidos, socavando al capitalismo liberal decimonónico y dando paso a una mayor intervención del Estado en la economía (Romero, 2016: 16).

En nuestro país este decenio se caracterizó por el desplome de mercados ${ }^{20}$ y una intervención estatal sin precedentes, convencida en transformar la cultura nacional. En el ámbito político, el recién creado Partido Nacional Revolucionario (PNR) aún no estaba plenamente consolidado de políticos, militares y civiles, favoreciendo así al ala izquierda del partido con su experiencia en la organización de obreros y campesinos. Una izquierda ${ }^{21}$ que aspiró a la formación de un partido nacional en oposición a las viejas élites terratenientes, propietarios extranjeros y la iglesia católica, que dominó la SEP desde 1932 a 1940, escribió el Plan Sexenal que dio rumbo a la presidencia de Lázaro Cárdenas de 1934 a 1940, y que encontró en éste a su máximo jefe y representante (Kay, 2001: 16). La economía política distintiva de esta década obedeció a la interacción entre dos fuerzas concurrentes, la posrevolución y la gran

\footnotetext{
${ }^{20}$ Para visualizar de manera más clara la dimensión de esta crisis se pueden revisar los datos que arroja el libro La politica de masas del Cardenismo de Arnaldo Córdova (1976: 17-18 ), entre éstos podemos mencionar que hasta 1935 el PIB volvió a los niveles de 1928, el ingreso público bajo en los primeros cinco años de este decenio de 322 a 212 millones de pesos, la inversión pública se redujo de 103 a 73 millones, el peso se fue devaluando año tras año, cayeron la producción de cereales, plomo y plata, así como el sector manufacturero, pese a que venía resistiendo de mejor manera el embate de la crisis.

${ }^{21}$ Barry Carr en La izquierda mexicana a través del siglo XX (1996: 61) describe cómo Cárdenas al tomar posesión elimina las restricciones contra la prensa del Partido Comunista Mexicano (PCM), ordena la liberación de los presos políticos y suprime el Departamento de Servicios Confidenciales de la Secretaría de Gobernación, principalmente por la persecución violenta de la izquierda. Ésta había sido fuertemente reprimida durante los gobiernos del Maximato (1930-1934). Durante el cardenismo se expropiaron las compañías petroleras de propiedad extranjera, se experimentó la autogestión obrera y campesina y se desarrolló una expansión masiva de la Reforma Agraria impactando al capitalismo del sector.
} 
depresión, cobrando mayor sentido en la administración y proyecto del cardenismo (Knight, 2015: 269).

La crisis económica impactó en las instituciones públicas mexicanas, y la Universidad Nacional no sería la excepción; el periodista Fernando Ramírez de Aguilar, bajo el seudónimo de "Jacobo Dalevuelta", describió puntualmente esta situación a principios de la década de los treinta:

La revolución estudiantil que tuvo como resultado inmediato la conquista de la autonomía universitaria creó a esta generosa institución la que, desgraciadamente, se abate en estos momentos merced a la crisis económica más fuerte que se haya registrado en toda su vida institucional. Sin embargo, a pesar de la penuria, a pesar de las angustias que padece la universidad, es por ahora el centro más respetable, interesante y revolucionario con que contamos dentro del país ("La Universidad Nacional Autónoma", Ilustrado del diario El Universal, 18 de agosto, 1932).

La Universidad Nacional ${ }^{22}$ no solamente fue afectada por las reducciones presupuestales gubernamentales derivadas de la crisis económica, sino también por los efectos legales de su propia autonomía. Desde octubre de 1929, la SEP informó a la Universidad que reduciría su partida del presupuesto de egresos, tras su autonomía; por lo que de conformidad con el artículo $7^{\circ}$ transitorio sólo tendría a su disposición la parte proporcional de las asignaciones que, en los presupuestos de la Secretaría de Agricultura y Fomento, Industria, Comercio y Trabajo y de Educación Pública, corresponden a las dependencias que les concede la Ley de Autonomía (AHUNAM, FUN, sección DA, c. 46, exp. 1440, f. 16991).
Las actividades de la recién creada Facultad de Música fueron mermadas en sus inicios, una de las pruebas contundentes es la respuesta de Eduardo Sánchez García, tesorero de la Universidad, a la petición de la Oficialía Mayor de la SEP - febrero de 1931 - para que ésta pusiera a disposición su agrupación musical representativa: "la orquesta de la facultad de música aún no está organizada, y por lo tanto no puede prestar su contingente para el festival en la Escuela Nacional de Maestros" (AHUNAM, FUN, sección DA, c. 64, exp. 2226, fs. 22647-22648).

\section{Imagen 6. Escudo distintivo de la Facultad de Música, enviado a Rectoría el 10 de agosto de 1931 para integrar un "cuadro general" de la Universidad y sus dependencias}

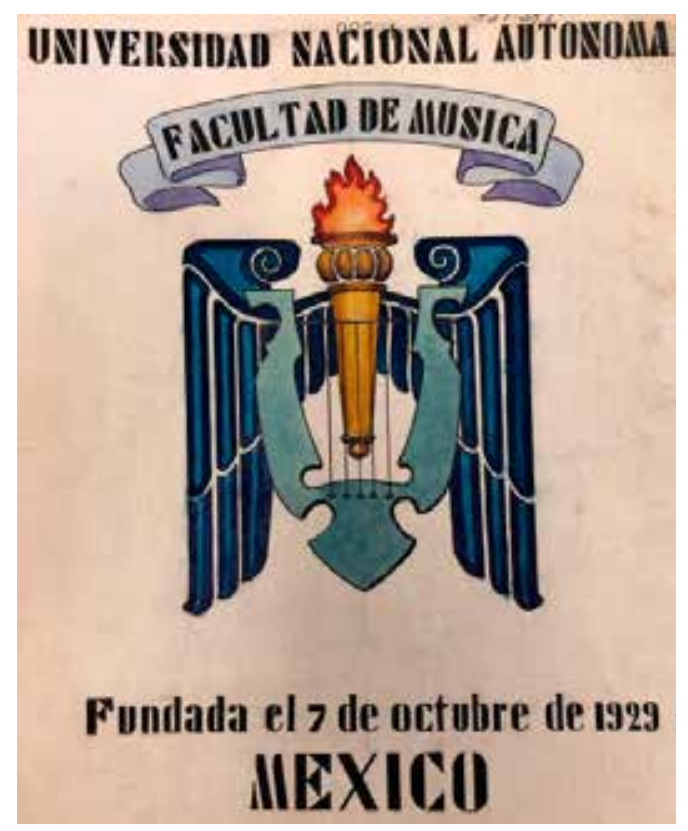

Fuente: AHUNAM, FUN, DA, exp. 535, f. 08985.

\footnotetext{
22 "Para cualquier institución nueva resulta difícil lograr grandes éxitos en poco tiempo; lo es más cuando ese tiempo incluye periodos turbulentos; sin embargo, es casi imposible alcanzarlos si además la nueva institución nace con errores graves. Este fue el caso de la Universidad Nacional, fundada dos meses antes de que estallara la Revolución mexicana, a partir de un proyecto débil y limitado. En rigor, la Universidad Nacional fue formada por la integración de las escuelas profesionales de Jurisprudencia, Medicina e Ingenieros; por la sección de Arquitectura, perteneciente a Bellas Artes; por la Escuela de Altos Estudios, única de nueva creación, y por la Preparatoria" (Garcíadiego, 1996: 119).
} 


\section{La Orquesta de la Facultad de Música (1931)}

La recién creada Facultad de Música continuó con sus actividades pese a las penurias económicas que enfrentaba la Universidad. La orquesta representativa de esta institución comenzó sus primeras actividades de difusión hasta mediados de 1931. El periódico El Universal (16/VI/1931) anunció de esta manera el primer concierto de la Orquesta de la Facultad de Música (OFM) de la Universidad Nacional Autónoma:

El domingo próximo, a las 11 horas, tendrá verificativo en el Anfiteatro "Bolívar", de la Escuela Nacional Preparatoria, el primer concierto de la Orquesta Sinfónica de la Facultad de Música, correspondiente a la Temporada 1931. El programa está formado por obras de verdadero mérito artístico, pues en el mismo figuran la "Obertura" Benvenuto Cellini, del genial compositor francés Héctor Berlioz, que será ejecutada por la Orquesta Sinfónica bajo la dirección del maestro Rocabruna; por tres obras de nuestro inspirado compositor y violinista Pedro Valdés Fraga, tituladas Romanza, para Chelo Solo, (que será desempeñada por el profesor Francisco Reyna), canción mexicana y Danza de Concierto, esta última para violín y piano y que será interpretada por los profesores Rodolfo Martínez Cortés y Miguel Meza. Estas obras obtuvieron el primer premio del segundo tema en el concurso convocado por la Universidad Nacional Autónoma. Figura, además, el Poema Sinfónico del compositor Alfonso de Elías, basado en la leyenda mexicana de Juan de Dios Peza "El callejón del Ave María", y cuya obra obtuvo el primer premio del primer tema en el concurso convocado por la Universidad Nacional Autónoma. Finalizará el programa con la cantata "Otoño", composición que también tomó parte en el concurso de referencia y que está escrita para cuatro voces mixtas, Solo y Orquesta. La soprano solista será la señorita Guadalupe G. Márquez y los conjuntos corales están constituidos por los mejores elementos de la Facultad de Música.

La OFM, integrada por 40 alumnos, no contaría con gratificaciones mensuales para sus integrantes por parte de la Universidad, como sí lo logró la anterior orquesta del conservatorio universitario; sin embargo, la falta de presupuesto del año corriente no consiguió mermar el objetivo de organizarse para hacer propaganda artística dentro de la universidad y revelar los caracteres musicales de la época (AHUNAM, FUN, sección DA, c. 61, exp. 2091, fs. 21849-21851). La OFM basó su operación en un reglamento, del cual destacan los siguientes puntos:

I. El nombre que llevará en todas sus actuaciones dicha orquesta será el de Orquesta de la Facultad de Música. II. Los componentes de dicha orquesta deben ser alumnos de la facultad. III. En el caso de que falten alumnos para completar la exigencia que requiere toda partitura de carácter sinfónico, estas plazas podrán ser cubiertas por profesionistas. IV. La orquesta se compondrá de 40 plazas (por el momento) [no se menciona en el documento el artículo $\mathrm{V}$, podría deberse a un error de redacción de este]. VI. Los alumnos que tengan carácter de practicantes no disfrutarán (por el momento) de la pequeña gratificación otorgada por la universidad. (a) Las vacantes que haya en dicha orquesta serán cubiertas por los que tengan carácter de practicantes considerando su aprovechamiento y a juicio del señor director de la facultad y director de la orquesta. VII. El director de la orquesta llevará una lista de asistencias y de faltas, quien la presentará mensualmente a la dirección de la facultad de música. VIII. La dirección de la facultad de música será la encargada de hacer la nómina mensualmente para el reparto equitativo de la dicha gratificación. IX. La orquesta de la facultad de música deberá ensayar cuando menos dos veces por semana los días y horas que indique el horario de la facultad de música. 
X. La orquesta de la facultad de música se presentará periódicamente en conciertos que organice la dirección y de común acuerdo con el director de la orquesta. XI. La orquesta de la facultad de música acompañará a los pasantes y alumnos aventajados las obras escritas con acompañamiento de orquesta como un estímulo a sus estudios. deberes de los alumnos que forman la orquesta. $1^{\circ}$. El alumno inscrito en la orquesta deberá asistir con la debida puntualidad a los ensayos y conciertos que organice la dirección de la facultad de música. $2^{\circ}$. El alumno deberá estudiar en lo particular y con entusiasmo la parte que le corresponde para el bien de él y el de la facultad de música. $3^{\circ}$. El alumno que tuviera durante el mes más de cuatro faltas no justificadas, la dirección podrá suspenderlo en sus demás clases. $4^{\circ}$. El alumno que faltase el respeto a sus superiores o compañeros, también a juicio de la dirección podrá suspenderlo en sus demás clases (según el reglamento interior de la facultad de música). $5^{\circ}$. La orquesta de la facultad de música tendrá un representante que nombrará la Sociedad de Alumnos, quien velará por los intereses de sus compañeros. $6^{\circ}$. La Sociedad de Alumnos podrá cambiar a su representante cuantas veces crea pertinente para el buen éxito de dicha corporación. Transitorios. (a) La dirección de la facultad de música al organizar los conciertos de la orquesta siempre procurará incluir alguna obra de autor nacional y en preferencia a las escritas por profesores o alumnos de la facultad. (b) La dirección procurará por todos los medios posibles obtener las obras sinfónicas que requiere toda entidad orquestal. México, D.F., a 13 de febrero de 1931. El director de la orquesta. José Rocabruna [Rúbrica] (AHUNAM, FUN, sección DA, c. 61, exp. 2091, fs. 21845-21848).
Imagen 7. José Rocabruna, director de la Orquesta de la Facultad de Música en su fundación

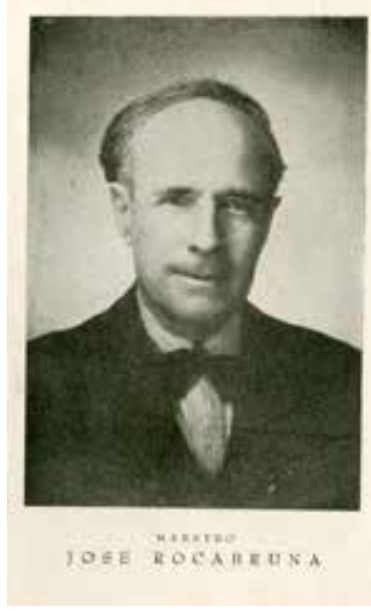

Fuente: Biblioteca Nacional, del Archivo de Iconoteca, Archivo de Expedientes.

\section{La Orquesta Sinfónica de la Universidad Nacional (1936)}

La Orquesta de la Facultad de Música sentó las bases para posteriormente constituirse como la Orquesta Sinfónica de la Universidad Nacional. ${ }^{23}$ En enero de 1936, las tareas de la extensión universitaria continuaron ahora dentro del recién creado Departamento de Acción Social bajo la dirección del Lic. Salvador Azuela ${ }^{24}$ y durante la rectoría del abogado Luis Chico Goerne. En la Revista de la Universidad de México de mayo en 1937, el propio Azuela describió puntualmente los "servicios" que integraron este departamento: Servicio Escolar para Trabajadores, ${ }^{25}$ Bibliotecas, Prácticas Escolares (consultorios y bufetes), Acción Estética, Editorial, Educación Física y Cursos de Verano. Las actividades musicales se impulsaron ahora a través del servicio de Acción Estética, así como también se patrocinaría una sociedad de conciertos:

\footnotetext{
${ }^{23}$ Hoy conocida como Orquesta Filarmónica de la Universidad Nacional Autónoma de México (OFUNAM).

${ }^{24}$ Este personaje fue hijo de Mariano Azuela, principal novelista mexicano del siglo XX. Salvador Azuela (1902-1983), cuando fue estudiante de preparatoria, apoyó la creación de "cursos libres" en 1918, y posteriormente participó en las cruzadas pedagógicas impulsadas por Vasconcelos.

${ }^{25}$ Se organizaron cinco centros obreros en el Distrito Federal en barrios de numerosa población proletaria como los de Santa Julia, Peralvillo, el Rastro, Tepito y las colonias de la Bolsa, Obrera e Hidalgo, y Escandón de Tacubaya. Estos centros llevaron nombres de próceres como Martí, Montalvo, Sarmiento, Giner de los Ríos, y Justo Sierra.
} 
"La sociedad filarmónica de méxico" es ya una plausible realidad. A nuestro culto colega José Barros Sierra, crítico musical de "El Universal" se debe que la Universidad Nacional Autónoma, por medio de su Departamento de Acción Social, haya acogido con todo entusiasmo esta iniciativa para crear una sociedad de $\operatorname{conciertos}^{26} \mathrm{y}$ hacer de México un centro musical de importancia (Ilustrado, 30/I/1936).

Para marzo de 1936, la batuta de la orquesta de la universidad también recayó en manos del maestro José F. Vázquez, quien en ese momento era más conocido como compositor que como director de orquesta:

La Universidad Nacional Autónoma nombró recientemente al maestro don José F. Vázquez, subdirector de la orquesta de la propia universidad, debido a sus méritos propios. En el proyecto que el maestro Vázquez presentó para las finalidades que perseguiría la Universidad Nacional, se aprobaron desde luego dos objetivos de suma importancia y trascendencia: la educación de las masas, que tendrá un aspecto popular y darles a los directores y compositores sin distinción de credos, toda clase de facilidades para que puedan presentar sus composiciones musicales y darlas a conocer en público. Estas son las finalidades, entre otras, que la Universidad Nacional Autónoma se propone desarrollar en el plano establecido para sus fines culturales (Ilustrado, 5/III/1936).

Pese a este nombramiento el maestro José Rocabruna, director desde los inicios de la OFM - ahora orquesta sinfónica de la universidad-, continuó participando en los conciertos de la Universidad dirigidos a los obreros:
El primer concierto popular de la universidad. La Universidad Nacional de México ofreció el primer concierto de la serie popular en el cine parque obrero "Venustiano Carranza", el 15 del presente mes, que correspondió al Departamento de Acción Social. El maestro José Rocabruna a quien se le encomendó la dirección de este festival, tuvo en cuenta el medio de expresarse musicalmente [...] El concierto a que hacemos referencia fue sujeto a estas características con el mejor éxito propuesto. Las obras tuvieron, además de una ejecución brillante y entusiasta por parte de la orquesta, verdadero interés y satisfacción del público que aplaudió con espontaneidad y calor, particularmente en dos números del programa que fueron bisados como el vals poético de Villanueva, que alcanzó algunos "bravos" y el vals "Se Sara Rose" de Arditi, que interpretó como solista la soprano Aurora Chávez. No obstante que en el programa hubo de intercalarse obras como la obertura "Egmont" de Beethoven y una sinfonía de F. E. Bach, el auditorio gustó de ambas obras y escuchó con el mayor silencio e interés las ejecuciones de la orquesta que en manos del maestro Rocabruna tuvo el acierto requerido para haber hecho de esa audición un largo rato de deleite espiritual en los obreros que con tanto gusto concurren a estos conciertos gratuitos con el mejor deseo de cultivarse (Ilustrado, 26/III/1936).

En los medios impresos, la orquesta sinfónica de la universidad se vincularía directamente con el Departamento de Acción Social:

El concierto de la universidad. Constituyó un éxito reciente el concierto desarrollado por la Orquesta Sinfónica del Departamento de Acción Social de la Universidad, ofrecido en el Anfiteatro "Bolívar" de la E. N. Preparatoria, en el que tomaron parte como directores los estimables maestros José Rocabruna,

\footnotetext{
${ }^{26}$ La Sociedad Filarmónica de México consiguió programar recitales de tríos prestigiosos como el de Barrere-Salzedo-Britt en el Teatro Arbeu, logrando abarcar programas de música clásica desde los siglos XVII y XVIII, hasta composiciones de vanguardia. Este trío estaba integrado por el flautista Georges Barrere, el arpista Carlos Salzedo y el cellista Horace Britt.
} 
José F. Vázquez y Juan D. Tercero. La pianista Carmen Azuela actuó como solista del Concierto de Grieg, dirigido por el maestro Vázquez, y demostró preparación y comprensión de la obra. Hubo aplausos para ella y para los maestros Vázquez y Rocabruna. En cuanto a la labor de los coros, volvemos a repetir lo que, en otras ocasiones, que dejan mucho que desear entre otras cosas por la desigualdad de las voces. El director Tercero debería seleccionar sus grupos (Ilustrado, 27/VIII/1936).

\section{Conclusiones}

Para conocer el complejo proceso de creación de la orquesta sinfónica de la Universidad Nacional es necesario escudriñar sus orígenes, los cuales se encuentran en sus distintos momentos nodales que revisamos en esta investigación: el conflicto de autonomía y la segregación del conservatorio de la universidad, la creación de la Facultad de Música y la puesta en marcha de su propia orquesta sinfónica dentro de un campo en un tiempo y espacio definido, en un contexto permeado por los gobiernos posrevolucionarios en el umbral de los difíciles años treinta en nuestro país.

Logrando cumplir con el objetivo principal de este artículo, no sólo se muestran elementos de pertenencia que fortalecen la identidad de los músicos universitarios antes y después del conflicto de autonomía, sino también los "debates" de las sesiones extraordinarias de las asambleas en donde los músicos del conservatorio universitario manifestaron su inconformidad al ser segregados del proyecto de autonomía. Estos músicos y alumnos, disidentes a la idea del maestro Chávez de insertar el conservatorio en las arterias de la SEP, realizaron una extraordinaria labor de convencimiento y argumentación ante la rectoría para crear una nueva escuela de música universitaria. Las asambleas programadas para esta nueva misión se convirtieron entonces en el espacio ideal para debatir sus "problemas comunes" en el campo de los músicos universitarios.
En los años posteriores, dentro del campo de los músicos universitarios se continuó exponiendo y debatiendo el tipo de músico que debería formar la universidad:

De este modo la Escuela trata de crear el tipo de músico culto, de aquel cuya cultura general pueda equipararse a la de los que abrazan otras carreras universitarias. Quiere que el músico salido de sus aulas no tan sólo sepa cantar bien o tocar bien un instrumento, sino que, además, tenga un criterio claro, preciso y sabiamente orientado sobre los múltiples problemas de la estética moderna. Es preciso que el músico universitario esté en condiciones de opinar sobre historia, sobre literatura, pintura, escultura, poesía; sobre cuestiones de cualquier otra índole, más o menos estrechamente relacionados con su profesión. En suma, la Escuela lucha sin descanso para formar, plasmar diríamos, al músico integral, y a la realización de este propósito se encaminan sus constantes esfuerzos (Conferencia impartida el 29 de agosto de 1939 por David F. España, a través de la Radio Difusora de la UNAM, AHUNAM, FENM, caja 24. Exp. 6, fs. 9282-9287).

Existieron visiones como las del profesor Estanislao Mejía, en donde el conservatorio y la escuela superior de música de la universidad debían "coordinar" sus enseñanzas:

para señalar el camino del arte más coherente, en la especialización de maestros, solistas, directores, técnicos para la enseñanza de especialidades teóricos-musicales y de metodología para la educación musical de los niños. Cada alumno graduado no sólo debe dominar la ejecución y conocimientos musicales de diversas tendencias y estilos, sino también familiarizarse con los métodos y procedimientos de enseñanza aplicados a todo trabajo pedagógico, así como a investigaciones científico-musicales, análisis, crítica, etc. (Ilustrado, 20/X/1938). 
Finalmente, en este artículo se sientan bases y se arrojan pistas para seguir investigando la transición del Departamento de Extensión Universitaria a Departamento de Acción Social, de la orquesta de la facultad de música a orquesta sinfónica de la universidad, así como de la labor, alcance y duración

\section{Referencias}

Aguirre Lora, María Esther (2008), Preludio y Fuga. Historias trashumantes de la Escuela Nacional de Música de la UNAM, México, Instituto de Investigaciones sobre la Universidad y la Educación (IISUE), UNAM/Plaza y Valdés.

Alvarado, María de Lourdes (2014), “Los nuevos espacios estudiantiles y la vocación cultural y social de la universidad", en Carlos Martínez Assad y Alicia Ziccardi (coords.), El barrio universitario. De la Revolución a la autonomía, México, UNAM, pp. 113-153.

Beristáin Cardoso, José Ángel (2019), “La Orquesta del Conservatorio en el seno de la Universidad Nacional (1917-1929)", en Revista Iberoamericana de Educación Superior (RIES), vol. X, núm. 27, pp. 93-113.

Beristáin Cardoso, José Angel (2018), "Política cultural en México. De la educación al entretenimiento", en Javier Tobar, Alberto Zárate y Javier Grosso (comps.), El patrimonio cultural en tiempos globales, Popayán, Colombia, Editorial Universidad del Cauca, pp. 201-220.

Bourdieu, Pierre (2011), Capital cultural, escuela y espacio social, México, Siglo XXI Editores.

Bourdieu, Pierre (2019), Homo academicus, México, Siglo XXI Editores.

Bourdieu, Pierre (2002a), Campo de poder, campo intelectual, Tucumán, Editorial Montressor.

Bourdieu, Pierre (2002b), La distinción. Criterios y bases sociales del gusto, México, Taurus. de la Sociedad Filarmónica de México que organizó también recitales y conciertos de música de cámara. Otra vertiente que puede seguirse en esta línea de investigación es el interdiscurso, es decir la construcción del imaginario del ambiente musical universitario a través de notas, artículos y críticas de la prensa.

Bourdieu, Pierre (1995), Las reglas del arte, México, Anagrama.

Cano Menoni, Agustín (2019), Cultura, nación y pueblo. La extensión universitaria en la UNAM (1910-2015), México, IISUE-UNAM.

Carmona, Gloria (comp.) (1997), Carlos Chávez. Obras I. Escritos periodísticos (1916-1939), México, El Colegio Nacional.

Carr, Barry (1996), La izquierda mexicana a través del siglo XX, México, Ediciones Era.

Carreño, G.C., G. Flores, I. Monroy y G. Villanueva (coords.) (2016), El Archivo Histórico de la UNAM. Cincuenta años de aportaciones y vinculación con la sociedad, México, IISUE-UNAM.

Córdova, Arnaldo (1976), La política de masas del Cardenismo, México, Ediciones Era.

Drinot, Paulo (2015), "Introducción", en Paulo Drinot y Alan Night (coords.), La Gran Depresión en América Latina, México, Fondo de Cultura Económica, pp. 11-35.

Gaceta UNAM (2001), "Suplemento de los 450 años de la Universidad de México", 12 de noviembre, México, UNAM.

Garcíadiego, Javier (1996), Rudos contra científicos. La Universidad Nacional durante la Revolución mexicana, México, Colegio de México/UnAM.

Gutiérrez López, Miguel Angel (2018), "Tres momentos de la autonomía universitaria en México", en Enrique Delgado López (Comp.), La autonomía universitaria en 
México. Estudios de caso, México, Universidad Autónoma de San Luis Potosí/IISUE-UNAM/Itaca, pp. 47-71.

Kay Vaughan, Mary (2001), La política cultural en la Revolución. Maestros, campesinos y escuelas en México, 19301940, México, Fondo de Cultura Económica.

Knight, Alan (2015), "Carácter y repercusiones de la Gran Depresión en México”, en Paulo Drinot y Alan Night (oords.), La Gran Depresión en América Latina, México, Fondo de Cultura Económica, pp. 269-307.

Lagorio, C. (2015), "Prólogo", en C. Lagorio, F. Cormick y A. A. Narvaja, Escenas y actores de una historia social y cultural, Buenos Aires, Universidad Nacional de Moreno, pp. 15-18.

Marsiske Schulte, Renate (2019), "Los protagonistas del movimiento estudiantil de 1929 en México y la autonomía universitaria”, en Hugo Casanova Cardiel, Enrique González González y Leticia Pérez Puente (coords.), Universidades de Iberoamérica: ayer y hoy, México, IISUE-UNAM, pp. 425-452.

Marsiske Schulte, Renate (2016), "La Universidad Nacional: creación, autonomía y marco normativo", en Hugo Casanova (Coord.), La UNAMy su historia. Una mirada actual, México, IISUE-UNAM [Historia de la Educación], pp. 151- 189.

Moreno Gamboa, Olivia (2009), Una cultura en movimiento. La prensa musical de la ciudad de México (1866-1910), México, UNAM/INAH.

Pérez Montfort, Ricardo (2015), "Auge y crisis del nacionalismo cultural mexicano, 1930-1960", en Ricardo Pérez Montfort (coord.), La cultura, 1808-2014, México, El Colegio de México - Centro de Estudios Históricos/Fundación Mapfre/Fondo de Cultura Económica, pp. 153-207.

Romero Sotelo, María Eugenia (2016), Los orígenes del neoliberalismo en México. La Escuela Austriaca, México, Fondo de Gultura Económica/UNAM.

Sapiro, Gisèle (2017), Las condiciones de producción y circulación de los bienes simbólicos (edición y presentación Laura Suárez de la Torre), México, Instituto Mora.

Storey,John (2002), Teoría culturaly cultura popular, Barcelona, Ediciones Octaedro.
Zanolli Fabila, Betty Luisa de María Auxiliadora (2017), La profesionalización de la enseñanza musical en México: El Conservatorio Nacional de Música (1866-1996. Su historia y vinculación con el arte, la ciencia y la tecnología en el contexto nacional, vol. I, México, Instituto Nacional de Bellas Artes y Literatura/ Conservatorio Nacional de Música. Ziccardi, Alicia (2014), "El barrio universitario: espacio público y acción estudiantil (1910-1929)", en Carlos Martínez Assad y Alicia Ziccardi (coords.), El barrio universitario. De la Revolución a la autonomía, México, UNAM, pp. 17-74.

\section{Fuentes documentales}

Biblioteca Nacional, del Archivo de Iconoteca, Archivo de Expedientes.

Archivo Histórico de la UNAM (AHUNAM), Instituto de Investigaciones sobre la Universidad y la Educación, UNAM.

- Fondo Universidad Nacional, sección Departamento de Administración

- Fondo Escuela Nacional de Música.

- Colección fotográfica Ricardo Salazar Ahumada.

\section{Fuentes Hemerográficas}

Hemeroteca Nacional de México:

Ilustrado, Revista Política del diario El Universal, 1929, 1932, 1938.

\section{Artículos en publicaciones periódicas}

Azuela, Salvador, "El Departamento de Acción Social de la Universidad", Revista de la Universidad de México, mayo, 1937.

Dalevuelta,Jacobo, "La UniversidadNacional Autónoma", Ilustrado del diario El Universal, 18 de agosto, 1932.

Mejía, Estanislao, "En el aniversario de la Escuela de Música de la Universidad", Ilustrado del diario El Universal, 20 de octubre de 1938.

Mejía, Estanislao, "Los fabricantes de crítica y las orquestas mexicanas", Ilustrado del diario El Universal, 24 de noviembre de 1938.

"El primer concierto de la Orquesta Sinfónica de la Facultad", El Universal, 16 de junio, 1931. 
Reyes, Víctor, "La música en México y en el extranjero", Ilustrado del Diario El Universal, 30 de enero de 1936.

Reyes, Víctor, "La música en México y en el extranjero", Ilustrado del Diario El Universal, 5 de marzo de 1936.
Reyes, Víctor, "La música en México y en el extranjero", Ilustrado del Diario El Universal, 26 de marzo de 1936.

Reyes, Víctor, "La música en México y en el extranjero", Ilustrado del Diario El Universal, 27 de agosto, 1936.

\section{Cómo citar este artículo:}

Beristáin-Cardoso, José-Ángel (2021), “Educación artística y autonomía universitaria en México: orígenes de la Orquesta Sinfónica de la Universidad Nacional (1929-1936)", Revista Iberoamericana de Educación Superior (RIES), vol. XII, núm. 33, pp. 77-100, DOI: https:// doi.org/10.22201/iisue.20072872e.2021.33.859 [Consulta: fecha de última consulta]. 